\title{
Ian S. Hornsey: Alcohol and its Role in the Evolution of Human Society
}

\author{
Matthew A. Ross
}

(C) Springer-Verlag Berlin Heidelberg 2012

$\begin{aligned} & \text { Alcohol and } \\ & \text { its Role in the } \\ & \text { Evolution of } \\ & \text { Human Society } \begin{array}{l}\text { Alcohol and its Role in the Evolution of } \\ \text { Human Society }\end{array} \\ & \text { lan S. Hornsey } \\ & \text { RSC Publishing, Cambridge, UK, 2012, pp xvii + } 665 \\ & \text { ISBN 978-1-84973-161-4 } \\ & \text { GBP 29.99 }\end{aligned}$

The author sets out to describe the origins of production of alcoholic beverages in this detailed tome. The focus is primarily on the genomics of the yeasts, cereals and other sugar sources used to produce drinks such as ale, wine, sake and mead. He draws on a wide range of evidence from the fields of botany, genetics, archaeology and history.

Although a considerable amount of information is included in the book the layout is somewhat awkward. The chapters are lengthy, and many subsections do not always remain entirely on topic. While the relationship between the genomics of a particular yeast strain, cereal or sugar source and alcohol production is usually made clear, the connection between those innovations in alcohol production and the evolution of human society is not always discussed in sufficient detail. The focus on genomics also means that for those without a significant amount of experience in this field, much of the book may be rather inaccessible. A lengthy introduction to acclimatize those unfamiliar with genomics with the language used may not have been feasible; however, changing the delivery of that

M. A. Ross $(\square)$

School of Life Sciences, Archaeological Sciences,

University of Bradford, Bradford, West Yorkshire, UK

e-mail: chromatographia@springer.com information could have helped the reader to better absorb and integrate the content of the book. Some of the most interesting sections are the ones in which Hornsey digresses from the topic of genomics and discusses particular social or cultural practices related to brewing. For example, I found myself pleasantly surprised to learn about the origins of each different sake classification as mandated by the Japanese Government, while reading through the section on the history of rice as a sugar source. However, these digressions typically last for only a few pages before the author turns back to genomics.

The chapters are divided into those focusing on ethanologenic organisms, the biochemistry of fermentation, grasses used for sugar, other sugar sources and anthropological and archaeological aspects of alcohol production. Case studies describing archaeological evidence for the production of alcoholic beverages are primarily found in the final section of the book, but are not ordered in any discernible way. Unfortunately, without a focus on separate regions over time or cases by region it can be difficult to understand what is known of how alcohol-related practices developed and spread between regions or what their ultimate impact has been on all of the different, distinct societies they have affected. Some case studies are mentioned and even discussed at length in earlier sections where they relate to particular sugar sources, but not every topic receives the same amount of attention. While this book is an excellent and diverse resource for those wishing to learn about historical brewing ingredients, practices and the genomics of the various sugar and yeast components used, the book is not formatted in a way that makes it accessible for casual reading. It serves better as a reference source on the history and development of the major constituents of alcoholic beverages than as a textbook on the influence of alcohol on the development of society. 